\title{
O cotidiano da Secretaria de Educação como espaço de formação para os Coordenadores
}

Pedagógicos

\author{
The everyday of the Secretariat of Education as a \\ training space for Pedagogical Coordinators
}

MARCIO BERNARDINO SIRINO (iDa

\section{Resumo}

Este presente ensaio tem por objetivo refletir sobre a possibilidade de formação aos coordenadores pedagógicos de dentro das Secretarias de Educação. Faz-se necessário sinalizar que esta construção se deu a partir de uma experiência, nesta função, na Secretaria Municipal de Educação, Ciência e Tecnologia (SECT), de Angra dos Reis/RJ, entre os anos 2012 e 2013. Por meio de uma escrita narrativa (ALVES; OLIVEIRA, 2001, OLIVEIRA, 2010, GARCIA; OLIVEIRA, 2015 e OLIVEIRA; SÜSSEKIND, 2016), em articulação com referenciais bibliográficos sobre a temática da coordenação pedagógica (ALMEIDA; PLACCO, 2010 e PLACCO; ALMEIDA, 2012), o texto tenciona as seguintes abordagens: atendimentos individuais, diálogos e embates, programas e projetos, relações interpessoais e sociais, reuniões de gerência, seleção de materiais, seminários, trabalho burocrático e visitas pedagógicas - evidenciando, no desfecho, que todos estes espaços formativos constituem a formação do coordenador pedagógico.

Palavras-chave: Espaço Formativo. Coordenação Pedagógica. Secretaria de Educação.

\footnotetext{
a Universidade Castelo Branco. E-mail: pedagogomarcio@gmail.com
} 
O cotidiano da Secretaria de Educação como espaço de formação para os Coordenadores Pedagógicos

\begin{abstract}
This essay aims to reflect on the possibility of training pedagogical coordinators within the Education Secretariats. It is necessary to signal that this construction took place from an experience, in this function, at the Municipal Secretariat of Education, Science and Technology (SECT), of Angra dos Reis/RJ, between the years 2012 and 2013. Through a narrative writing (ALVES; OLIVEIRA, 2001, OLIVEIRA, 2010, GARCIA; OLIVEIRA, 2015 and OLIVEIRA; SÜSSEKIND, 2016), in conjunction with bibliographic references on the theme of pedagogical coordination (ALMEIDA; PLACCO, 2010 and PLACCO; ALMEIDA, 2012), the text intends the following approaches: individual assistance, dialogues and clashes, programs and projects, interpersonal and social relationships, management meetings, selection of materials, seminars, bureaucratic work and pedagogical visits - showing, in the end, that all these training spaces constitute the training of the pedagogical coordinator.
\end{abstract}

Keywords: Formative Space. Pedagogical Coordination. Secretariat of Education.

\title{
Resumen
}

Este ensayo tiene como objetivo reflexionar sobre la posibilidad de formar coordinadores pedagógicos dentro de las Secretarías de Educación. Es necesario señalar que esta construcción se dio a partir de una experiencia, en esta función, en la Secretaría Municipal de Educación, Ciencia y Tecnología (SECT), de Angra dos Reis/RJ, entre los años 2012 y 2013. A través de un escritura narrativa (ALVES; OLIVEIRA, 2001, OLIVEIRA, 2010, GARCIA; OLIVEIRA, 2015 y OLIVEIRA; SÜSSEKIND, 2016), en conjunto con referencias bibliográficas sobre el tema de la coordinación pedagógica (ALMEIDA; PLACCO, 2010 y PLACCO; ALMEIDA, 2012), el texto pretende los siguientes enfoques: asistencia individual, diálogos y enfrentamientos, programas y proyectos, relaciones interpersonales y sociales, reuniones de gestión, selección de materiales, seminarios, trabajo burocrático y visitas pedagógicas - demostrando, al final, que todos estos espacios de formación constituyen la formación del coordinador pedagógico.

Palabras clave: Espacio formativo. Coordinación Pedagógica. Secretaria de Educación. 
Há educação, é claro, na escola e na família, mas ela também se verifica nas bibliotecas e nos museus, num processo de educação a distância e numa Brinquedoteca. Na rua, no cinema, vendo televisão e navegando na internet, nas reuniões, nos jogos $e$ brinquedos (mesmo que eles não sejam dos chamados educativos ou didáticos) etc. ocorrem, igualmente, processos de educação.

(Jaume Trilla)

\section{Introdução}

A partir das contribuições de Ferreira, Sirino e Mota (2019), em articulação com epígrafe trazida no início desta introdução, podemos afirmar que todos os espaços sociais são produtores de significativas aprendizagens. Pode ser a escola, a casa, a igreja, a rua, enfim, diversos lugares.

Esta aprendizagem se dá na interação que o ser humano estabelece com o outro por meio da diversidade de percepções, das trocas constantes, da vivência com o diferente e do conflito de ideias provocados nos diálogos e momentos oportunos de reflexão e tomada de decisão.

Este panorama de aprendizagem/formação coloca em evidência que um coordenador pedagógico não é escolhido de maneira aleatória, pois precisa ser alguém competente e com conhecimentos técnicos e pedagógicos de acordo com a área em que vai atuar e, ainda, coadunar com a visão de educação e política adotadas na atual gestão (ALMEIDA; PLACCO, 2010 e PLACCO; ALMEIDA, 2012).

Cabe destacar que o simples fato de, num pequeno espaço, estar reunidas várias pessoas com diferentes visões sociais de mundo, do homem e da sociedade, vindas de diversas localidades e participantes de variados grupos sociais já se pode acreditar na troca e na aprendizagem que pode ocorrer, mas, além de tudo isso, acrescenta-se, no bojo, a formação profissional que cada um possui e suas experiências de vida que, juntas, compõem o saber individual que, ao ser socializado, possibilita a construção de um saber coletivo (PLACCO; SOUZA, 2012).

Saber este que pode ser identificado na Secretaria de Educação, uma vez que se encontram pessoas de diferentes áreas do conhecimento, o que favorece na Rev. Caminhos da Educação: diálogos, culturas e diversidades, Teresina, v. 3, n. 2, p128-142, Mai./Ago. 2021 
O cotidiano da Secretaria de Educação como espaço de formação para os Coordenadores Pedagógicos

composição de uma equipe plural e com uma multiplicidade de saberes e fazeres que, a cada dia, se desenvolvem e se formam neste espaço.

Cabe sinalizar que a formação não se dá apenas no nível profissional, pois, enquanto seres humanos, nós somos um todo. Cada um de nós possui uma vida singular, uma história pessoal, uma formação profissional, uma saúde emocional e uma maneira de agir, embasada nas concepções que adotamos e, com isso, todas as diferentes dimensões formadoras dos sujeitos caminham juntas, de forma integrada (GUARÁ, 2006).

Quando uma destas áreas não está bem resolvida, as outras padecem e sentem suas dores, por sua vez, no momento em que um campo se desenvolve e se aperfeiçoa, automaticamente, os outros também passam por um processo de evolução. Ou seja, é uma aprendizagem global e uma formação mais qualificada na vida e em todas as áreas que dela fazemos parte.

Nesta busca, cabe ponderar que a formação de um coordenador pedagógico é muito importante e deve acontecer a todo instante, pois ele é uma referência para um grupo ou categoria e, desta forma, deve aproveitar todos os momentos para refletir sobre a sua prática, as relações que se processam nos espaços em que está inserido e as possibilidades de intervenção e modificação das diversas realidades por meio do conhecimento construído e reconstruído a cada dia e, ainda, da ousadia em enfrentar as dificuldades e propor soluções (PLACCO; SOUZA, 2012).

É importante destacar que o Coordenador Pedagógico é responsável por uma atuação eficaz que atenda às necessidades da sua equipe de trabalho e mobilize outros a repensarem suas práticas e se engajarem com a causa maior que é a promoção de uma educação de qualidade (PARO, 2001).

Neste sentido, na Secretaria de Educação, o coordenador é participante de um grupo que está à frente de uma área para garantir que ela se desenvolva e que suas 
abrangências aconteçam nas unidades escolares da melhor maneira possível. E, para que o coordenador consiga fazer o seu efetivo papel, é imperioso que ele se permita aprender com todas as pessoas e em todos os espaços.

Perspectiva esta que nos aproxima das contribuições do grande educador Paulo Freire, patrono da nossa educação brasileira, quando dizia que "Não há um sem o outro, mas ambos em permanente integração” (FREIRE, 2005, p. 41). Esta construção tão conhecida vem reforçar o compromisso que cada um deve ter de valorizar o conhecimento do outro e analisar tudo que lhe vem ao seu alcance, absorvendo novas informações e construindo outros saberes neste processo relacional, pois na integração com o outro, nós nos constituímos enquanto humanos, educadores, coordenadores e sujeitos.

Este processo de integração é imperioso em todos os espaços sociais, sobretudo na Secretaria de Educação, pois os coordenadores que fazem parte dela convivem com outros coordenadores que possuem um grande potencial de formar e de se formarem pelo contato, diálogo, enfrentamento ou pelo fato de estarem próximos fisicamente, que embora pareça não contribuir, na verdade, é muito importante, na medida em que possibilita o desenvolvimento da capacidade de olhar para o outro, criar um conceito, analisá-lo e, mesmo sem a troca de nenhuma palavra, atuar de maneira profissional, ética e humana.

Esta atuação é um exercício que, sendo realizado a cada dia, promove uma formação muito importante para cada coordenador pedagógico. Uma formação para além das paredes das Secretarias de Educação. Uma formação em sua vida.

\section{Formação dos Coordenadores}

Embora seja consenso a importância da formação obtida por meio da participação de cursos, seminários, assessorias, palestras e grandes eventos, há vários teóricos que pesquisam o cotidiano como espaço de formação (ALVES; OLIVEIRA, 2001, OLIVEIRA, 2010, GARCIA; OLIVEIRA, 2015, OLIVEIRA; SÜSSEKIND, 2016), pois o ser humano aprende de diferentes formas e em distintos espaços sociais. 
O cotidiano da Secretaria de Educação como espaço de formação para os Coordenadores Pedagógicos

O simples contato com outros contextos, espaços e departamentos já possibilita uma formação profissional e pessoal para qualquer educador. Cabe ressaltar que o coordenador pedagógico possui uma dinâmica de trabalho muito intensa na Secretaria de Educação: ele vivencia, a cada dia, conflitos e embates, deve tomar decisões, trabalhar com o outro, respeitar o diferente e, ainda, se reciclar constantemente.

Nenhum curso, por mais bem estruturado e contextualizado que seja, pode dar conta das demandas do dia-a-dia. Com isso, percebe-se que o simples fato de agir e refletir já promove uma formação muito importante a estes sujeitos.

Concepção esta, pesquisada por Paulo Freire e afirmada como sendo exigência para todo educador nas seguintes colocações: "A reflexão sobre a prática se torna uma exigência da relação Teoria/Prática sem a qual a teoria pode ir virando blablabá e a prática, ativismo" (FREIRE, 1996. p. 22).

Partindo desta articulação entre teoria e prática, hibridizando os saberes construídos cotidianamente com as contribuições teórico-metodológicas de pesquisadores que se debruçam sobre a temática da formação docente, podemos ressaltar que variados são os momentos em que os coordenadores pedagógicos são instigados a pensar e reformar o seu próprio pensamento, refletir sobre sua prática e se formar, pois, de acordo com Silva (2012), o coordenador pedagógico é:

Aquele que durante o ano articula a sua equipe em torno do melhor cumprimento do que foi estabelecido, coordenando seus diversos desdobramentos: planejamento, acompanhamento e avaliação (p. 58).

\section{Atendimento Individual}

Uma vez por semana, os coordenadores se organizam para efetuar o atendimento individual. Neste momento, ocorre uma troca mais efetiva e pontual Rev. Caminhos da Educação: diálogos, culturas e diversidades, Teresina, v. 3, n. 2, p128-142, Mai./Ago. 2021 
entre duas pessoas. Os assuntos suscitados permitem que se intervenha, dê um atendimento diferenciado, personalizado e que, ainda, se trabalhe a se trabalhe a escuta ao outro, uma escuta sensível como Hoffmann (2014) pontua a partir do relato de René Barbier.

Em 1992, René Barbier (Universidade 8, Paris) iniciou uma palestra dizendo que "conhecimento e experiência não são suficientes para se chegar à verdade!" Desenvolvendo a tese sobre a "Escuta sensível em educação", ele fez-me refletir sobre certas posturas dos professores com os quais nos deparamos e a necessária sensibilidade dos supervisores e coordenadores de projetos para entende-los em seus posicionamentos (p. 169 e 170).

É uma ação muito importante, pois o educador que vem ao encontro do coordenador pedagógico, traz um anseio e uma necessidade específicos. Ele carece de um olhar humanizado e de um cuidado especial.

E essa postura é possível nos momentos de atendimento individual que, em muitas vezes, o coordenador acredita estar passando uma formação para o educador e fornecendo orientações, mas, na verdade, nesta interação o coordenador pedagógico está aprendendo e se formando na medida em que está em efetiva troca com o outro, pois, como afirma Freire (1996), "quem forma se forma e re-forma ao formar e quem é formado forma-se e forma ao ser formado" (p. 23).

\section{Diálogos e Conflitos}

Há muitas demandas presentes no cotidiano da Secretaria de Educação. São várias tarefas para dar conta e, nesse meio, às vezes, muita discordância se faz presente. Discordância porque cada um traz consigo compreensões diferenciadas sobre o mesmo processo formativo. Estas diversidades de concepções promovem, a cada dia, embates e muito diálogo.

A percepção de que o ser humano cresce e se desenvolve a partir do diálogo e da interação com o outro faz com que os momentos de embate não sejam vistos como perda de tempo e nem como desgastes na relação entre os coordenadores, mas, sim, como oportunidade de trabalhar com o diferente, aprender a sustentar as ideias 
O cotidiano da Secretaria de Educação como espaço de formação para os Coordenadores Pedagógicos

e defendê-las, criar mecanismos para coadunar pensamentos diversos e desenvolver a tolerância para com o outro.

De acordo com Jares (2008), criador da Pedagogia da Convivência, o diálogo pode ser percebido como um fator essencial para melhorar a qualidade de vida das relações humanas. Certamente, nestes momentos de diálogo, o embate será inevitável, pois estão em jogo diferentes significações sobre educação, prática pedagógica, formação docente e muitas outras frentes de trabalho no interior da Secretaria de Educação. O problema não é o conflito estabelecido, mas, sim, a forma como se tenta resolvê-lo. Resolvendo estes conflitos/embates com diálogo abre-se a possibilidade de fortalecer a convivência humana, mas, tentando resolver de forma violenta, automaticamente o espaço educativo fica insustentável e a convivência prejudicada.

\section{Programas e Projetos}

Na Secretaria de Educação, há inúmeros projetos e programas que, juntos, lutam pela causa maior que é a promoção de uma educação de qualidade. Os coordenadores que estão à frente destes projetos, possuem a oportunidade de estudar e se aprofundar nas temáticas que transversalizam o cotidiano das escolas e se aprimorar nos conhecimentos específicos das áreas de conhecimento que envolvem cada projeto ou cada programa (VEIGA, 1995).

Há coordenadores da área de leitura, meio ambiente, diversidade, uso indevido de drogas, turismo, sexualidade, música e tantos mais que, dentro da sua especificidade, colaboram para a construção de uma educação melhor para os nossos alunos.

O coordenador aprende e se desenvolve a cada momento, pois, na Secretaria, cotidianamente estão presentes representantes de todos estes programas e projetos, cada um com uma história de vida e uma formação diferentes que, na troca e nas Rev. Caminhos da Educação: diálogos, culturas e diversidades, Teresina, v. 3, n. 2, p128-142, Mai./Ago. 2021 
próprias conversas (RIBEIRO; SOUZA; SAMPAIO, 2018) de bastidores, se é possível verificar uma formação profissional muito eficiente.

Conversas estas que ajudam a compor o repertório formativo, pois, assim, cada coordenador tem a oportunidade de conhecer um pouco mais de outras áreas que constituem sua gerência, seu setor e, assim, poder oferecer instruções e orientações adequadas em seus atendimentos, direcionando diretores, professores, educadores e profissionais da educação para o serviço que melhor atende às demandas apresentadas.

\section{Relações Interpessoais e Sociais}

Todos os lugares em que estamos inseridos, criamos laços, estabelecemos relações. Com o tempo, algumas relações vão ficando desgastadas, outras sucateadas e outras literalmente acabadas. Mas, estas relações, fazem com que percebamos como todos os espaços sociais representam a nossa sociedade verdadeiramente. Uma sociedade que promove a interação com o outro e o fortalecimento do contato.

Mas, existe uma subjetividade na vivência com o outro. E o coordenador pedagógico deve ter muita clareza quanto a seu envolvimento com ele no interior da Secretaria de Educação, pois se não houver um equilíbrio, invertem-se os papéis e a ética e o profissionalismo ficam em segundo plano.

Placco (2012) traz uma reflexão potente sobre as relações interpessoais e pedagógicas que se dão no interior da sala de aula. Perspectiva esta que pode ser, de igual forma, assimilada no interior da Secretaria de Educação, na atuação do coordenador pedagógico, pois, segunda a autora, "A qualidade da interação estabelecida é fundamental para que a construção e a transformação cognitivoafetivo-social de cada um dos parceiros ocorram na direção do desenvolvimento de ambos, como pessoas" (PLACCO, 2012, p. 63).

A reflexão sobre a própria postura adotada do coordenador já garante uma formação muito relevante para a sua vida e dos demais sujeitos que com ele convivem. Uma formação para além dos muros da secretaria em que se faz pensar como se 
O cotidiano da Secretaria de Educação como espaço de formação para os Coordenadores Pedagógicos

processam as relações e como elas se aprofundam ou se liquidificam (BAUMAN, 2004) na nossa sociedade.

\section{Reuniões de Gerência}

Momentos em que todos os coordenadores param, se reúnem e dialogam sobre suas demandas, suas conquistas e seus anseios. Os informes são repassados, as necessidades são postas e, juntos, há a possibilidade de construção coletiva de alguma pendência ou projeto.

A gerência, por ficar responsável por todas as coordenações de sua área, fica com uma demanda muito grande de trabalho e uma responsabilidade tamanha. Espaços como esse promove uma aproximação entre as partes e os coordenadores, além de possibilitar uma efetiva troca e mais um momento de formação em serviço. Formação esta imprescindível para todos os coordenadores pedagógicos.

Nas reuniões de gerência, compreendemos o trabalho dos outros coordenadores, suas frentes de atuação, seus planejamentos e envidamos esforços coletivos para a realização de eventos, dinamização de processos formativos e, ainda, pensamos sobre a educação pública que queremos ajudar a construir.

Com Paro (2001) encontramos pistas de uma discussão potente sobre a gestão da educação ante as exigências de qualidade e produtividade da escola pública. Uma reflexão que, a todo momento, perpassa os diálogos estabelecidos no interior da Secretaria de Educação na medida em que os educadores que ali exercem o ofício de coordenadores pedagógicos articulam, a todo momento, diferentes sentidos sobre qualidade da educação e tencionam as exigências de produtividade (im)postas.

Uma potência que aflora nas reuniões de gerência na busca por construir um processo formativo que questione as práticas inadequadas e ofereça condições de construir outras possibilidades de atuação, mais participativas, mais transparentes, Rev. Caminhos da Educação: diálogos, culturas e diversidades, Teresina, v. 3, n. 2, p128-142, Mai./Ago. 2021 
mais autônomas, mais descentralizadas e, consecutivamente, mais democráticas (COTRIM, 1988)

\section{Seleção de Materiais}

Todos os Coordenadores estão à frente de um grupo de educadores e de uma área de atuação. Por isso, é sempre necessário rever os materiais, fazer uma seleção e propor novos instrumentos de trabalho.

Neste singelo tempo, em que se faz uma seleção e se pensa no dia-a-dia do educador que está na escola, precisando de um apoio e de um suporte de qualidade, o coordenador se forma.

Ele pesquisa os materiais, faz inferências, planeja, dialoga com outras partes e fortalece parcerias importantes para que toda a categoria pela qual o coordenador é responsável seja beneficiada e assessorada.

Faz-se necessário destacar que este movimento se configura como espaço formativo, pois, a todo momento, o coordenador está em contato com o universo acadêmico, identificando na literatura, novos olhares sobre o processo formativo, contribuições recentes que possam ser dinamizadas em reuniões, visitas pedagógicas e atendimentos individuais.

Contribuições que ofereçam instrumentos reflexivos para o avançar na prática educativa e que coloquem em pé de igualdade o exercício da docência com a necessidade da discência, pois, como preconiza o eterno Freire (1996), "Não há docência sem discência, as duas se explicam e seus sujeitos apesar das diferenças que os conotam, não se reduzem à condição de objeto, um do outro” (p. 23).

\section{Seminários}

A realização de um seminário é uma tarefa muito árdua, pois envolve a questão financeira, a disponibilidade de vinda dos palestrantes, a hospedagem, a alimentação e toda a parte de divulgação e logística. 
O cotidiano da Secretaria de Educação como espaço de formação para os Coordenadores Pedagógicos

É um trabalho que demanda tempo e investimento, mas que, ao mesmo tempo, se configura um momento ímpar na formação do coordenador. Ao entrar em contato com diversos órgãos, setores e repartições, o coordenador se propõe a fazer o melhor para que o evento se realize da melhor maneira possível. Este movimento faz com que ele se empenhe, reflita, faça escolhas e estas atitudes contribuem na construção de um coordenador mais competente e qualificado.

Um exercício que oportuniza a construção de uma formação compartilhada, como sinalizam Cunha e Prado (2012), na medida em que os diferentes espaços de formação oportunizados possibilitam "o desenvolvimento pessoal e profissional dos professores e coordenadores. Trata-se de medidas e importâncias que elegemos para orientar a co-formação possível e desejável” (p. 47).

\section{Trabalho Burocrático}

A demanda de um coordenador é muito grande. São fichas para preencher, telefonemas a efetuar, e-mails a enviar, licitações a participar, formações a promover e muita papelada para colocar em dia.

Estes momentos, embora sejam cansativos e técnicos demais, são de extrema importância para a prática do coordenador, pois esta ação atribui legitimidade ao trabalho do coordenador e o ancora nos pilares de uma gestão, supostamente, democrática, a saber: participação, autonomia, descentralização e transparência (ABREU, 2017).

Deixando tudo registrado e organizado o coordenador desenvolve um trabalho de qualidade, coerente com a proposta em que está inserido e se torna um exemplo para o seu grupo. Ele se forma neste espaço e tempo em que percebe a importância de deixar suas demandas em dia e seus documentos, devidamente, 
preenchidos por entender que isso dará veracidade ao trabalho, irá dirimir as dúvidas suscitadas e, ainda, sistematizará as ações realizadas.

\section{Visitas Pedagógicas}

Cada escola é uma realidade distinta, no continente ou na ilha, no sertão ou na aldeia. O coordenador, ao chegar a uma unidade escolar, para a realização de uma visita pedagógica, ele tem como objetivo conhecer o cotidiano, promover uma formação para os profissionais que lá estão inseridos e, ainda, intervir de maneira adequada, respeitando, obviamente, o contexto e as especificidades de cada escola.

Mas, a formação quem recebe, na verdade, é o próprio coordenador. A interação que ele recebe, nos diferentes espaços sociais pelos quais ele passa, faz com que ele construa um cabedal de conhecimentos nas vivências obtidas em cada visita, onde o coordenador tem a oportunidade de pensar junto com o coletivo em soluções pedagógicas para os dilemas que orbitam o plano social em que a escola está inserida (CALIMAN, 2010).

O olhar, o ouvir, o pensar e o sentir se fazem presentes de maneira única na vida do coordenador nestes momentos de visita. Idas e vindas, conhecimentos e informações compartilhados, efetiva troca e possibilidade de intervenção. Esta formação é humana e alcança todas as esferas do coordenador pedagógico.

\section{Considerações finais}

O coordenador pedagógico aprende em todos os espaços em que ele está inserido e esta formação é muito mais do que técnica ou profissional, é uma formação humana que perpassa diferentes dimensões formadoras dos sujeitos.

E, na Secretaria de Educação, não é diferente. É um espaço formativo ímpar no qual o coordenador forma e é formado, por meio de atendimentos individuais, diálogos e embates, programas e projetos, relações interpessoais e sociais, reuniões de gerência, seleção de materiais, seminários, trabalho burocrático e, ainda, visitas 
O cotidiano da Secretaria de Educação como espaço de formação para os Coordenadores Pedagógicos

pedagógicas, frentes de atuação que constituem a formação do coordenador pedagógico.

Com isso, verifica-se a importância de se perceber o cotidiano da Secretaria de Educação, lugar onde se encontram os coordenadores pedagógicos, como espaço de formação. Uma formação global, construída a cada dia nos pequenos e grandes momentos vivenciados dentro e fora deste espaço.

O Espaço da Secretaria de Educação...

Espaço de diálogo,

Espaço de reflexão,

Espaço de troca,

Espaço de interação.

Espaço de vivências,

Espaço de tecer,

Espaço de qualidade

E de formação obter.

\section{Referências}

ABREU, Valéria Fernandes de. Gestão Democrática em Escolas de Tempo Integral: um olhar sobre as ações de gestores escolares. 2017. Dissertação (Mestrado em Educação) - Programa de Pós-Graduação em Educação, Universidade Federal do Estado do Rio de Janeiro (PPGEdu/UNIRIO): Rio de Janeiro, 2017.

ALMEIDA, Laurinda Ramalho; PLACCO, Vera Maria Nigro de Souza. (Orgs.). O coordenador pedagógico e o atendimento à diversidade. São Paulo: Edições Loyola, 2010. 
ALVES, Nilda. OLIVEIRA, Inês Barbosa de. (Orgs.). Pesquisa no/ do cotidiano das escolas: sobre redes de saberes. Rio de Janeiro: DP\&A, 2001.

BAUMAN, Zygmunt. Amor líquido: sobre a fragilidade dos laços humanos. Rio de Janeiro: Zahar, 2004.

CALIMAN, Geraldo. Pedagogia Social: seu potencial crítico e transformador. Revista de Ciências da Educação, Americana, ano 12, n. 23, p. 341-368, 2º sem. 2010.

COTRIM, Gilberto. Educação para uma escola democrática: história e filosofia da educação - $2^{\mathrm{a}}$ ed.- São Paulo: Saraiva, 1988.

CUNHA, Renata Barrichelo; PRADO, Guilherme do Val Toledo. Sobre importâncias: a coordenação e a co-formação na escola. In.: PLACCO, Vera Maria Nigro de Souza; ALMEIDA, Laurinda Ramalho. (Orgs.). O coordenador pedagógico e os desafios da educação. São Paulo: Edições Loyola, 2012. (p. 37-49).

FERREIRA, Arthur Vianna; SIRINO, Marcio Bernardino; MOTA, Patricia Flavia. (Orgs.). Espaços produtores de aprendizagem nos distintos espaços sociais. Coleção Práticas e Teorias da Pedagogia Social, v. 5. Jundiaí/SP: Paco Editorial, 2019.

FREIRE, Paulo. Pedagogia da Autonomia: saberes necessários à prática Educativa. São Paulo: Paz e Terra, 1996.

FREIRE, Paulo. Pedagogia do Oprimido. 48ª reimp. Rio de Janeiro: Paz e Terra, 2005.

GARCIA, Alexandra; OLIVEIRA, Inês Barbosa de. (Orgs.). Nilda Alves: praticantepensante de cotidianos. Belo Horizonte: Autêntica Editora, 2015.

GUARÁ, Isa Maria Ferreira de Rosa. É imprescindível educar integralmente. Cadernos CENPEC, São Paulo, n. 2, p. 15-24, 2006. 
O cotidiano da Secretaria de Educação como espaço de formação para os Coordenadores Pedagógicos

HOFFMANN, Jussara. Avaliação Mediadora: uma prática em construção da pré-escola à universidade. 33 ed. Porto Alegre/RS: Mediação, 2014.

JARES, Xesús Rodríguez. Pedagogia da Convivência. São Paulo: Palas Athena, 2008.

OLIVEIRA, Inês Barbosa de. (Org.). Narrativas: outros conhecimentos, outras formas de expressão. Petrópolis/RJ: DP et al. Rio de Janeiro/RJ: FAPERJ, 2010.

OLIVEIRA, Inês Barbosa de; SÜSSEKIND, Maria Luiza. (Orgs.). Formação docente e justiça cognitiva: pesquisa, práticas e possibilidades. Rio de Janeiro: DP et al, 2016.

PARO, Vitor Henrique. Escritos sobre Educação. São Paulo: Xamã, 2001.

PLACCO, Vera Maria Nigro de Souza. A sala de aula como lócus de relações interpessoais e pedagógicas. In.: PLACCO, Vera Maria Nigro de Souza; ALMEIDA, Laurinda Ramalho. (Orgs.). O coordenador pedagógico e os desafios da educação. São Paulo: Edições Loyola, 2012. (p. 61-73).

PLACCO, Vera Maria Nigro de Souza; ALMEIDA, Laurinda Ramalho. (Orgs.). O coordenador pedagógico e os desafios da educação. São Paulo: Edições Loyola, 2012.

PLACCO, Vera Maria Nigro de Souza; SOUZA, Vera Lucia Trevisan de. Desafios ao coordenador pedagógico no trabalho coletivo: intervenção ou prevenção? In.: PLACCO, Vera Maria Nigro de Souza; ALMEIDA, Laurinda Ramalho. (Orgs.). O coordenador pedagógico e os desafios da educação. São Paulo: Edições Loyola, 2012. (p. 25-36).

RIBEIRO, Tiago; SOUZA, Rafael de; SAMPAIO, Carmem Sanches. (Orgs.). Conversa como metodologia de pesquisa: por que não? Rio de Janeiro: Ayvu, 2018. 
SILVA, Moacyr da. O trabalho articulador do coordenador pedagógico: a integração curricular. In.: PLACCO, Vera Maria Nigro de Souza; ALMEIDA, Laurinda Ramalho. (Orgs.). O coordenador pedagógico e os desafios da educação. São Paulo: Edições Loyola, 2012. (p. 51-59).

VEIGA, Ilma Passos Alencastro. Projeto político-pedagógico da escola: uma construção possível. Campinas, SP: Papirus, 1995.

RECEBIDO: 04/4/2021

APROVADO: 04/05/2021
RECEIVED: 04/04/2021

APPROVED: 04/05/2021
RECIBIDO: 04/04/2021

APROBADO: 04/05/2021 